Discussion Paper No. 06-030

\title{
Economic Effects of
} VAT Reform in Germany

Stefan Boeters, Christoph Böhringer, Thiess Büttner and Margit Kraus

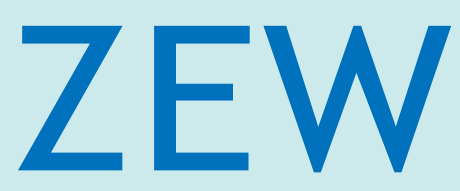

Zentrum für Europäische Wirtschaftsforschung $\mathrm{GmbH}$

Centre for European

Economic Research 
Discussion Paper No. 06-030

\title{
Economic Effects of VAT Reform in Germany
}

\author{
Stefan Boeters, Christoph Böhringer, \\ Thiess Büttner and Margit Kraus
}

Download this ZEW Discussion Paper from our ftp server:

ftp://ftp.zew.de/pub/zew-docs/dp/dp06030.pdf

Die Discussion Papers dienen einer möglichst schnellen Verbreitung von neueren Forschungsarbeiten des ZEW. Die Beiträge liegen in alleiniger Verantwortung der Autoren und stellen nicht notwendigerweise die Meinung des ZEW dar.

Discussion Papers are intended to make results of ZEW research promptly available to other economists in order to encourage discussion and suggestions for revisions. The authors are solely responsible for the contents which do not necessarily represent the opinion of the ZEW. 


\section{Non-Technical Summary}

Reflecting distributional concerns, many countries apply VAT reductions to goods which make up a larger share in the consumption of low-income households. This paper addresses the question to what extent VAT differentiation can be rationalised on distributional grounds.

We employ an applied general equilibrium (AGE) model to investigate distributional effects and efficiency implications for structural VAT reforms based on empirically data for Germany. In our numerical simulations we compare a pure VAT reform, where the differentiated VAT is replaced with a uniform rate, and scenarios in which the additional revenues are compensated with tax reductions involving the marginal income tax rate (MITR), the income tax allowance (ITA) or the social security contributions (SSC).

Our main findings can be summarised as follows: The abolition of the reduced VAT rate in itself has only a small redistributive effect towards more inequality. Therefore, VAT differentiation can hardly be considered as an effective means of redistribution policy. When we compensate the abolition of reduced VAT rates with reductions in the marginal income tax rate or cuts in social security contributions, there is scope for significant gains in overall welfare. A budget compensation scheme based on a reduction in the income tax allowance, however, produces welfare losses, due to the implied increase in the marginal tax burden. Policy-induced changes in macroeconomic indicators like GDP, employment, domestic capital use, or aggregate consumption echo this welfare ranking of the tax instruments. While the distributional effects of VAT reforms are within a relatively narrow range, the industry effects (in terms of variation in industry output) are much more pronounced. This indicates that the VAT rate differentiation can be viewed primarily as an industry-specific subsidy rather than an instrument of redistribution. From a political economy point of view, the sectoral implications highlight lobbying interests of adversely affected sectors to work against changes of the actual VAT structure. 


\title{
Economic Effects of VAT Reform in Germany
}

\author{
Stefan Boeters ${ }^{\circ}$, Christoph Böhringer ${ }^{\ddagger+*}$, \\ Thiess Büttner ${ }^{\dagger}$, Margit Kraus ${ }^{\ddagger}$ \\ ${ }^{\ddagger}$ ZEW, Mannheim, $\quad{ }^{\circ} \mathrm{CPB}$, Den Haag \\ ${ }^{+}$Department of Economics, University of Heidelberg \\ ${ }^{\dagger}$ Ifo Institut and Department of Economics, Munich University
}

April 2006

\begin{abstract}
In the tax policy debate, differentiation of value-added taxes is often justified by distributional concerns. Our quantitative analysis for Germany indicates that such concerns are misplaced. We find that the abolition of VAT differentiation has only negligible redistributive effects. Instead, reduced VAT are found to act as industry-specific subsidies. Whereas the overall welfare effects of pure VAT reforms are very small, a revenue-neutral introduction of a harmonised VAT combined with reductions in the marginal income tax rates or social security contributions turns out to produce substantial welfare gains for all households.
\end{abstract}

Keywords: VAT, tax reforms, distribution, efficiency, applied general equilibrium

JEL Code: D58, H22, H24

${ }^{*}$ Corresponding author: Christoph Böhringer, Centre for European Economic Research, P.O.Box 103443, 68034 Mannheim, Germany, e-mail: boehringer@zew.de 


\section{Introduction}

Consumption taxation through value-added taxes (VAT) is usually considered as a relatively efficient way of raising public funds. Theoretical analysis points to the neutrality of VAT with respect to intertemporal consumption decisions, whereas income taxes tend to distort the trade-off between consumption and savings. On the other hand, a uniform VAT is often criticised on the basis of its allegedly regressive distributional effects. Reflecting distributional concerns, many countries apply VAT reductions to specific goods, which make up a larger share in the consumption of low-income households. In the EU, all countries but one use reduced VAT rates for specific consumption commodities. Especially in the old EU member states VAT reductions on food, water, medication, and public transport are quite common (European Commission, 2005).

This paper addresses the question to what extent VAT differentiation can be rationalised on distributional grounds. VAT differentiation is an indirect instrument of distribution as it is not associated with the individual ability to pay of different consumers. There are more direct instruments of distributive policy such as income taxation or monetary transfers. Thus, from an applied policy perspective, we must be concerned with how large the redistributive effects of VAT differentiation are in practice, and whether or not alternative policy instruments are more effective as redistributive devices. Answers to these concerns cannot be given by abstract theoretical considerations. They depend on the precise type of products favoured by VAT reductions and the demand and supply conditions on the respective markets, which are determined by household preferences, production technologies, factor endowments, and the market structure. ${ }^{1}$

In this paper, we employ an applied general equilibrium (AGE) approach to investigate efficiency and distributional impacts for structural VAT reforms based on

\footnotetext{
${ }^{1}$ In the public finance literature a number of reasons are mentioned why VAT differentiation might be justified under efficiency considerations: (i) administrative and compliance costs (Keen and Mintz, 2004), (ii) the existence of shadow markets, (iii) differences in price elasticities of goods, or (iv) complementarity of consumption goods with untaxed leisure activities. However, these reasons are either difficult to ascertain on empirical grounds (due to the lack of data) or irrelevant in policy practice. (As a prime example VAT reductions are applied to goods with inelastic demand such as food, which is contrary to optimal taxation reasoning.) More recently, VAT reductions have also been proposed as a measure to stimulate employment in labour intensive service industries.
} 
empirically observed data for Germany. The AGE approach provides a comprehensive framework for studying the effects of policy interference on all markets of an economy, rigorously based on microeconomic theory. The simultaneous consideration of the origin and spending of the agents' income makes it possible to address both economy-wide efficiency as well as distributional impacts of policy regulation. This has made AGE models a standard tool for the quantitative analysis in many policy domains including fiscal, trade and environmental policy.

The strand of AGE literature that is directed to the analysis of VAT reforms is relatively small compared to other public finance issues such as income taxation or pension reform: Ballard et al. (1987) analyse VAT in the USA as a possibility to increase the dynamic efficiency of the tax system. Hamilton and Whalley (1989) use a static model to explore special intricacies of the interaction of federal and provincial taxes in Canada. Gottfried and Wiegard (1991) focus on the implementation of the VAT and compare two different institutional settings, tax exemption vs. zero rating, for the German economy. Dixon and Rimmer (1999) use a dynamic model for Australia to investigate VAT reforms with a special focus on the induced international trade effects. In a more recent paper, Åvitsland and Aasness (2004) combine a dynamic AGE and a microsimulation model to assess VAT reform scenarios for Norway.

In Germany, the VAT has a standard and a reduced rate. The latter applies mostly to food, public transport, and print-media products. We use our AGE model to simulate variants of a revenue-neutral abolition of the reduced VAT rate. The results of the simulations confirm doubts about the effectiveness of reduced VAT rates as a redistributive instrument and point to welfare gains from uniform taxation. These welfare gains are boosted if taxes other than VAT are included in the tax reform. Among alternative sources of revenue which keep the overall budget constant (tax recycling instruments), revenue-neutral reductions in marginal income tax rates and - in particular - cuts in the social security contributions provide larger welfare gains. At the sectoral level, the reduced VAT rate works mainly as a subsidy to the respective final-goods producers and their intermediate-input suppliers.

The remainder of this paper is organised as follows. Section 2 gives an overview of the model structure and parametrisation. Section 3 provides the results of the scenario simulations. Section 4 concludes. 


\section{Model and Parametrisation}

For our simulation analysis we draw on a standard AGE model which has been refined to address central issues of VAT reforms. ${ }^{2}$ Specific extensions include the disaggregation of the household sector into income terciles, where each tercile has a special income composition and consumption structure. For the empirical parametrisation of the model, various data sources are used including the German Input-Output Table for 1997, the production-consumption transition matrix - the so-called "Z-matrix", and the German Income and Expenditure Survey (EVS) have been combined to form a consistent benchmark dataset.

In the following, we first summarise the basic features of our AGE model (Section 2.1). A detailed description of the household representation follows in Section 2.2. Finally, we discuss data and calibration issues (Section 2.3). A comprehensive algebraic summary of the model is provided in the appendix.

\subsection{Basic Model Structure}

\section{Firms and factors of production}

The AGE model underlying our VAT reform analysis for Germany features 69 production sectors. In each sector, output is produced from intermediate inputs, capital, and labour of two skill types (high skilled and low skilled). Production possibilities are characterised through nested constant-elasticity-of-substitution (CES) production functions, which describe the trade-off between various inputs. Perfect competition implies that there are no pure profits. The primary factors labour and capital are remunerated according to their respective marginal productivities. Cost minimisation by firms yields demand functions for production inputs at the sectoral level.

The domestic labour market is characterised through frictions and equilibrium unemployment. We make use of a wage-curve relationship in which the rate of unemployment is linked to the degree of progressivity of the income tax due to an implicit wage-bargaining mechanism (Koskela and Vilmunen, 1996). Capital is fully mobile

\footnotetext{
${ }^{2}$ Specifically adapted refinements of the standard model have been applied recently to the climate policy debate (Böhringer and Lange, 2005) and labour market policies (Böhringer, Boeters, and Feil, 2005).
} 
across sectors, and the domestic capital market is perfectly competitive. At the international level, domestic and foreign capital are treated as imperfect substitutes to account for less than perfect international capital mobility. The calibration of the respective parameters is discussed in Section 2.3.3.

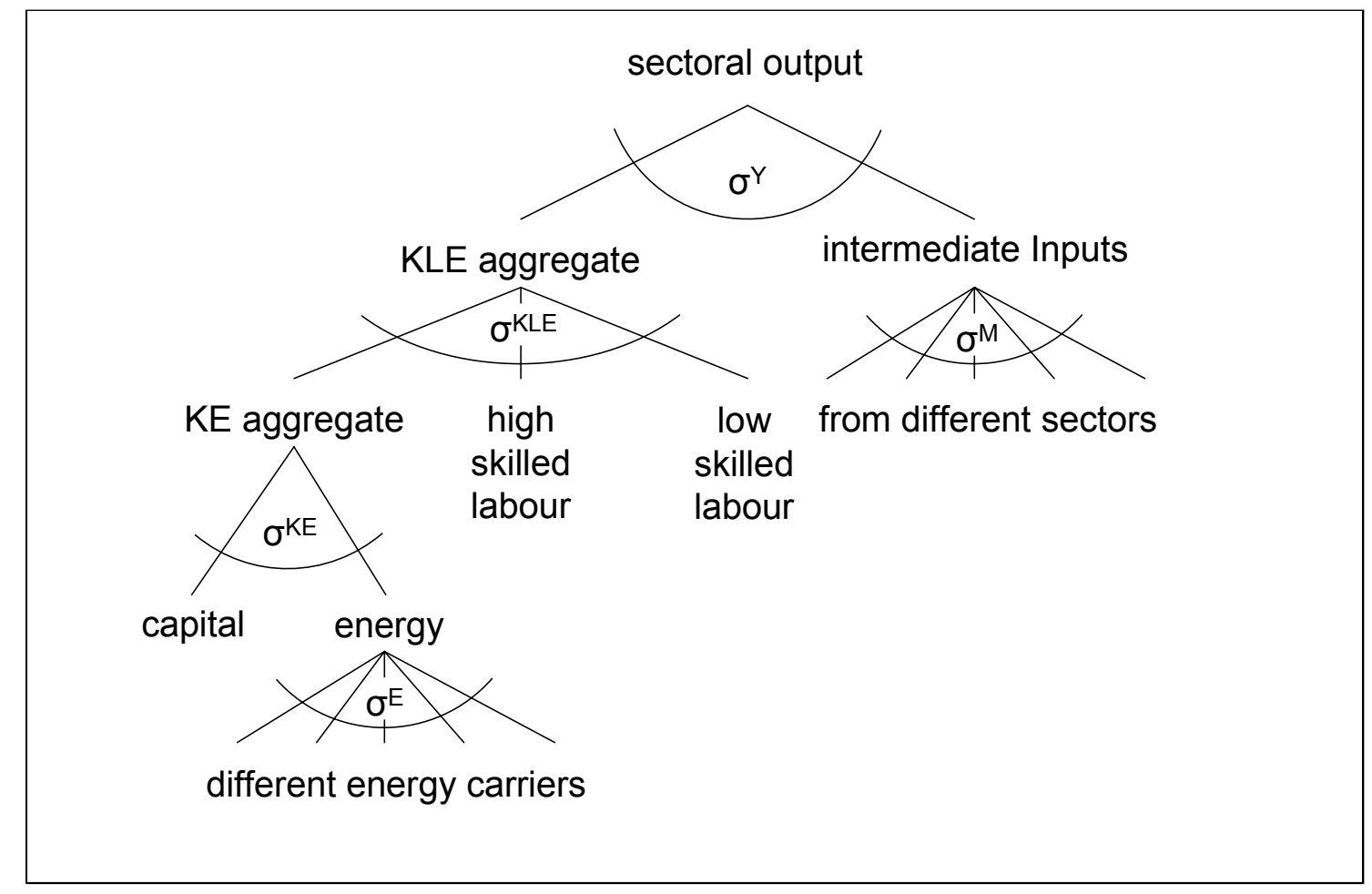

Figure 1: Production structure for a representative sector

In Figure 1 we adopt the following notation:

$$
\begin{aligned}
\sigma^{Y}:= & \begin{array}{l}
\text { elasticity of substitution between the aggregate of intermediate pro- } \\
\text { duction inputs and the input composite of labour, capital and en- } \\
\end{array} \\
& \text { ergy, } \\
\sigma^{K L E}:= & \text { elasticity of substitution between the capital-energy aggregate and } \\
& \text { (skilled as well as unskilled) labour, } \\
\sigma^{M}:= & \text { elasticity of substitution between intermediate inputs entering the } \\
& \text { sectoral composite of intermediate inputs, } \\
\sigma^{K E}:= & \text { elasticity of substitution between capital and aggregate energy, } \\
\sigma^{E}:= & \text { elasticity of substitution between different energy carriers entering } \\
& \text { the aggregate energy input. }
\end{aligned}
$$




\section{Foreign trade}

Domestically produced goods are converted through a constant-elasticity-of-transformation function into goods destined for the domestic market and the export market, respectively. Export and import prices in foreign currency are considered as exogenous (small-open-economy assumption). Analogously to the export side, we adopt the Armington assumption of product heterogeneity for imports. A CES function characterises the trade-off between imported and domestically produced varieties of the same good. The Armington good enters intermediate and final demand. Foreign closure of the model is warranted through the balance-of-payments constraint.

\section{Government budget}

Given our focus on VAT reform, the model emphasises the role of consumption taxation. The VAT captures differences across consumption categories with three levels of the tax rate (full rate, reduced rate, and tax exempt goods). Furthermore, we account for the indirect impact of value-added taxation in the production of goods which are tax exempt. Besides the VAT, direct taxes and social security contributions of households are differentiated by household types. Social security contributions are assumed to be proportional to labour income while income taxation takes the form of a linear progressive schedule (tax allowance combined with a constant marginal tax rate). Finally, the model contains sectoral output taxes and subsidies as well as import and export levies.

\section{Private households}

We distinguish three representative households capturing the lower, middle, and upper tercile of the income distribution. Each household takes a labour-leisure decision and chooses between different consumption goods. Details about the characteristics of the disaggregated households are provided in the following section.

\subsection{Representation of the Household Sector}

\subsubsection{Household Disaggregation}

The private household sector is disaggregated into three households representing, respectively, the lower, middle and upper income tercile of the households according to the German Income and Expenditure Survey (EVS). The EVS is a representative household survey by the German Federal Statistical Office. The 1998 sample 
comprises 62.000 households. The first part of the survey reports data on household structure, housing situation, financial and tangible assets as well as debt. The second part contains income and expenditure items adapted to the classification of the input-output accounts.

Households are grouped into the three income terciles according to their "equivalent household income". Household income is divided by the respective number of household members in order to compare households of different sizes. We use the square root of the household size as equivalence scale to compute the respective number of household members, thereby reflecting economies of scale due to fixed costs in household consumption. ${ }^{3}$ The income and expenditure values of the three fictitious representative households are then set to the arithmetic mean of the respective income class.

Table 1 summarises basic characteristics of the household types. Disposable income - the sum of the rows "consumption" and "savings" - varies substantially across the three terciles. Taking the first tercile as the basis of comparison, disposable income of the second tercile is higher by roughly one half, whereas the disposable income of the third tercile is three times as high. Less than two thirds of gross income (or not even more than one third as in the case of the first tercile) are made up of factor income. The residual income consists mainly of transfer payments, pensions and private credit (with "savings" meaning gross savings). The income tax schedule is progressive as can be seen from the average and marginal tax rates ${ }^{4}$; in addition, we report the implicit tax allowances associated with a linear progressive income tax scheme. Average social security contributions (SSC) are decreasing in income due to an assessment threshold for the base of SSC.

Labour supply of the representative households is split into skilled and unskilled labour by summing up skill-specific incomes of all individual households in the respective tercile. We assume a uniform wage per skill type which amounts to an efficiency weighting of individual working hours. Furthermore, the unemployment rate is assumed to be uniform across households (but different for the skill types) and is calculated by summing up employed and unemployed persons in the terciles. We count the registered unemployed as involuntary unemployed while the unemployed that are not registered are classified as voluntary unemployed.

Table 2 reports the consumption shares of the household terciles by VAT categories.

\footnotetext{
${ }^{3}$ Cf. e.g. Biewen (2000) or Atkinson et al. (1995, 18ff.) for alternative scales.

${ }^{4}$ The percentage numbers are given relative to gross factor income.
} 


\begin{tabular}{lccc}
\hline \hline & lower tercile & middle tercile & upper tercile \\
\hline Consumption & $1738(78 \%)$ & $2317(62 \%)$ & $3674(51 \%)$ \\
Savings & $256(11 \%)$ & $788(21 \%)$ & $2427(33 \%)$ \\
Taxes and SSC & $237(11 \%)$ & $618(17 \%)$ & $1179(16 \%)$ \\
Factor income & $753(34 \%)$ & $2045(55 \%)$ & $4385(60 \%)$ \\
Other income & $1477(66 \%)$ & $1678(45 \%)$ & $2895(40 \%)$ \\
Average tax rate & $10.0 \%$ & $12.8 \%$ & $16.5 \%$ \\
Average SSC & $23.5 \%$ & $20.4 \%$ & $12.7 \%$ \\
Marginal tax rate & $14.9 \%$ & $16.1 \%$ & $22.1 \%$ \\
Implied tax allowance & 247 & 417 & 1127 \\
\hline \hline
\end{tabular}

Rows (1) to (5): absolute values in $€$ per month and percentage values as shares in gross income; rows (6) to (8): percentage of factor or labour income, respectively

Table 1: Household characteristics according to EVS

It can be seen that the share of the three VAT categories in consumption is rather stable (upper part of Table 2). This is especially the case for the tax-exempt goods, while the shares of the reduced-rate goods are slightly decreasing and those of the full-rate goods are slightly increasing in income. The figures in Table 2 already suggest that a differentiated VAT rate may not be well suited as a redistributive device. In relation to the disposable income (lower part of Table 2), the share of all VAT categories is decreasing, simply because of the increasing propensity to save.

\begin{tabular}{cccc}
\hline \hline & lower tercile & middle tercile & upper tercile \\
\hline Share in consumption & & & \\
VAT 0\% & $38.8 \%$ & $37.2 \%$ & $37.2 \%$ \\
VAT 7\% & $27.3 \%$ & $25.6 \%$ & $23.7 \%$ \\
VAT 15\% & $33.9 \%$ & $37.2 \%$ & $39.1 \%$ \\
\hline Share in disposable income & & & \\
VAT 0\% & $33.8 \%$ & $27.7 \%$ & $22.4 \%$ \\
VAT 7\% & $23.8 \%$ & $19.1 \%$ & $14.3 \%$ \\
VAT 15\% & $29.5 \%$ & $27.8 \%$ & $23.6 \%$ \\
\hline \hline
\end{tabular}

Table 2: Household consumption structure

The expenditure shares of the consumption good categories are calculated as fractions of the so-called "income available for expenditures". The latter is defined as 
the sum of disposable income, sales of goods and property, pensions from private insurances, liquidation of financial and tangible assets and from bank and consumption credit loans. The household budget is then balanced by the residual income category called "other income" (see Table 1). The expenditure categories of the EVS are subjected to several adjustments in order to warrant consistency with the 12-goods-classification of the Z-matrix. In order to enable us to discuss a structural VAT reform detailed EVS expenditure shares for each of the 12 categories have been grouped into categories with VAT of 16 percent, 7 percent or tax exemption, respectively. Corresponding data has been provided by the German federal statistical office in the form of a special Z-matrix differentiated according to VAT rates.

\subsubsection{Consumption Structure}

The consumption structure of the three representative households is reflected in the nesting of multi-level utility functions adopted within the numerical AGE model (see Figure 2). Current utility is composed of commodity consumption and leisure (of the two skill varieties). Commodity consumption in turn is an aggregate of food consumption and other consumption goods (which are then further decomposed at the lower level). Food consumption is explicitly represented because it is the most important consumption goods category to which the reduced VAT rate is applied in Germany. All consumption good categories are finally broken down into the three VAT categories (tax exempt goods, reduced and full VAT rate) according to their empirical shares (see Table 2). At the top, the utility tree might be extended by the decision between current and future consumption. We make this margin of substitution exogenous by fixing the volume of savings for each of the households.

In Figure 2 we adopt the following notation:

$$
\begin{aligned}
\sigma^{U}:= & \text { elasticity of substitution between current consumption and leisure, } \\
\sigma^{C}:= & \text { elasticity of substitution between food and the non-food consump- } \\
& \text { tion aggregate, } \\
\sigma^{L E}:= & \text { elasticity of substitution between leisure of high skilled and low } \\
& \text { skilled labour, } \\
\sigma^{V A T}:= & \text { elasticity of substitution between commodities subject to (three) } \\
& \text { different VAT categories, } \\
\sigma^{N F}:= & \text { elasticity of substitution between consumption commodities enter- } \\
& \text { ing the non-food consumption composite. }
\end{aligned}
$$




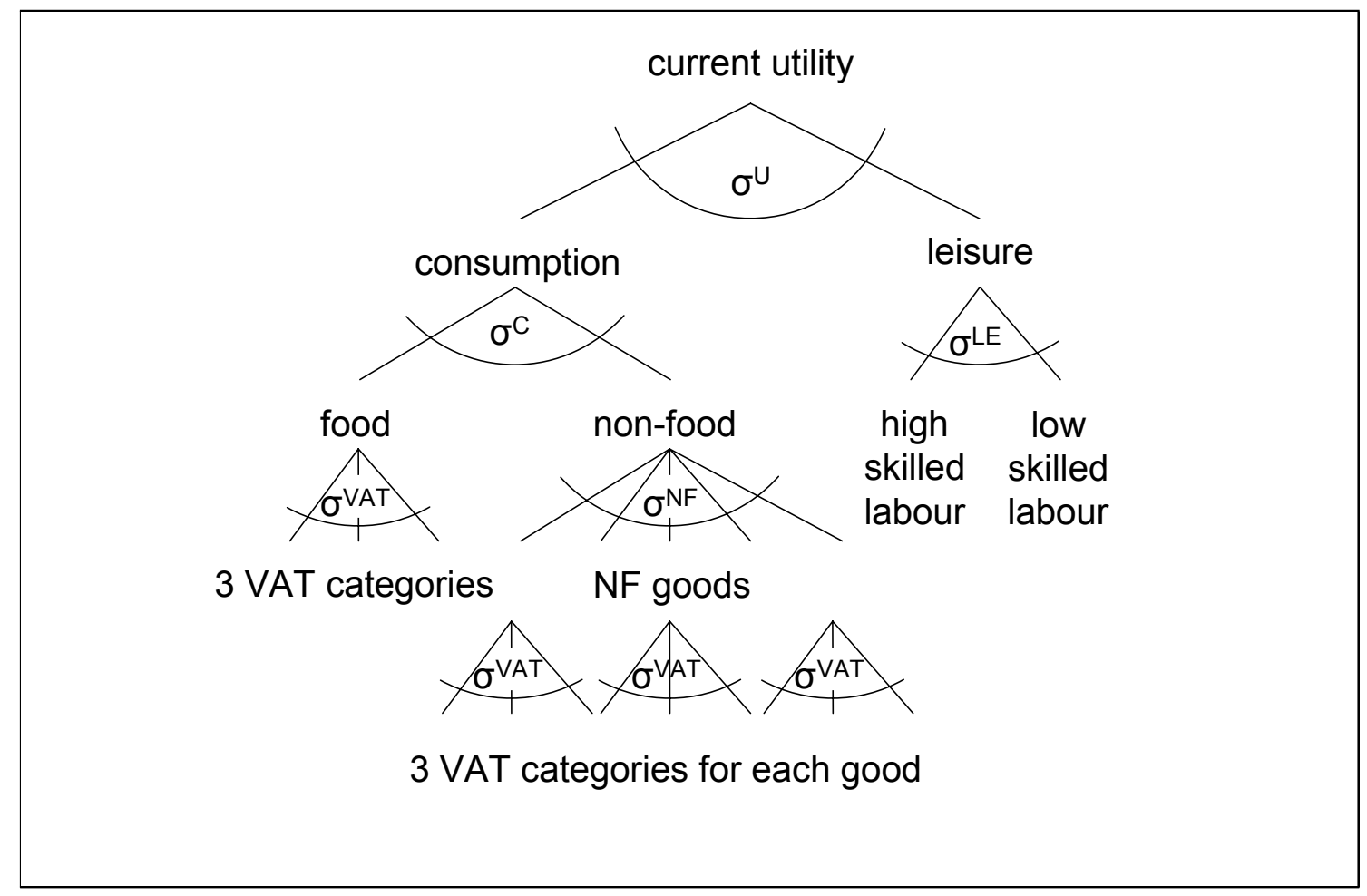

Figure 2: Consumption structure of representative household

\subsection{Parametrisation}

\subsubsection{Input-Output Data}

In a comparative-static analysis, policy effects are assessed with respect to a reference situation - the benchmark - where no policy changes apply. The benchmark is typically determined by economic transactions in a particular benchmark year. As is customary in applied general equilibrium analysis, benchmark quantities and prices - together with exogenous elasticities - are used to calibrate the model. They determine the free parameters of the functional forms that capture production technologies and consumer preferences.

We use the input-output table of the German federal statistical office for the year 1997 as the central data source for model calibration. The first quadrant of the input-output table reports intermediate inputs for each sector. The second quadrant provides information on final demand components: private and public consumption, investment, inventory changes, and exports. Factor payments to labour and capital (combined with profits in the row "operating surplus") are included in the third 
quadrant which also reports the inflows of foreign goods and services to each production sector. As to taxes, the standard input-output table records product-specific taxes and subsidies as well as the VAT.

Output by production sector is linked to consumption by private households in terms of expenditure categories through the Z-matrix, see above.

\subsubsection{Calibration of the Utility Function}

The calibration of the parameters of the utility function (see Figure 2) requires the integration of empirical estimates for labour supply and consumption demand.

\section{Labour supply elasticity}

The utility function (see appendix for the algebraic specification) includes leisure of two skill types implying uncompensated labour supply elasticities, $\varepsilon_{h, j}$, for household $h$ and skill type $j$ :

$$
\varepsilon_{h, j}=\left(\zeta_{h}-1\right)\left[\sigma_{h}^{L E}\left(1-\theta_{h, j}\right)+\sigma_{h}^{U} \theta_{h, j}\left(1-\theta_{L E, h, j}\right)+\theta_{h, j} \theta_{L E, h, j}-\theta_{I, h, j}\right]
$$

where

$\zeta_{h}:=$ labour endowment as a multiple of actual labour supply,

$\theta_{h, j} \quad:=$ share of leisure of type $j$ in all leisure,

$\theta_{L E, h, j}:=$ share of the leisure aggregate in total current utility,

$\theta_{I, h, j}:=$ share of labour endowment of type $j$ in extended income, (including leisure and non-labour income).

With exogenous shares, labour supply $(\zeta)$ set to 1.75 (70 hours of weekly labour endowment relative to an average weekly working time of 40 hours), and given the elasticities $\varepsilon_{h, j}$, it is straightforward to invert the two equations (1), $j=$ high, low skilled, for the unknown elasticities $\sigma^{L E}$ and $\sigma^{U}$. Our reading of the empirical literature on labour supply elasticities (for a survey see, e.g., Borjas, 2000) is that there are no strong results on skill- or income-bracket-specific labour supply elasticities and that uncompensated labour supply elasticities are centred around 0.15. So we calibrated the model to $\varepsilon_{h, L}=\varepsilon_{h, H}=0.15$. 


\section{Consumption demand elasticities}

At the lower nests of the utility tree of Figure 2, taking the upper-level elasticities as given, we can solve recursively for the elasticities of interest, $\sigma^{C}$ and $\sigma^{N F}$ :

$$
\begin{aligned}
\sigma_{h}^{C}= & \frac{1}{1-\theta_{h, F}}\left[-\varepsilon_{F}-\sigma_{h}^{U} \theta_{h, F}\left(1-\theta_{h, C}\right)+\theta_{h, F} \theta_{h, C}\right] \\
\sigma_{h}^{N F}= & \frac{1}{1-\bar{\theta}_{h, N F}}\left[-\bar{\varepsilon}_{N F}-\sigma_{h}^{C} \bar{\theta}_{h, N F}\left(1-\theta_{h, N F}\right)\right. \\
& \left.-\sigma_{h}^{U} \bar{\theta}_{h, N F} \theta_{h, N F}\left(1-\theta_{h, C}\right)-\bar{\theta}_{h, N F} \theta_{h, N F} \theta_{h, C}\right]
\end{aligned}
$$

where

$\varepsilon_{F} \quad:=$ own-price elasticity of food demand,

$\bar{\varepsilon}_{N F}:=$ average own-price elasticity of demand for non-food goods,

$\theta_{h, C}:=$ share of consumption in current utility,

$\theta_{h, F}:=$ share of food in the consumption goods aggregate,

$\theta_{h, N F}:=$ share of all non-food goods in the consumption goods aggregate,

$\bar{\theta}_{h, N F}:=$ average share of individual non-food goods in the non-food aggregate.

With respect to the price elasticities of consumption demand we draw on Chen (1999), who estimates consumption demand parameters for 42 OECD countries. Chen uses a differential estimation approach according to Theil (1980) and assumes preference indifference. His estimates for Germany and the mean of the estimates for the 42 countries investigated are given in Table 3. Due to differences regarding the definitions of product categories, we only distinguish between the price elasticity of food (-.222) and the average price elasticity for the remaining 7 categories (-.563) in the model.

\subsubsection{Calibration of International Capital Mobility}

The calibration of the production structure in Figure 1 is a standard exercise in AGE modelling, except for the part that concerns international capital mobility. We have capital mobility in two directions: capital imports and capital exports. For the elasticity of capital imports with respect to the domestic interest rate, $\varepsilon_{K M}$, we can calculate from the production function (Figure 1):

$$
\varepsilon_{K M}=\sigma^{K}\left(1-\theta_{K M}\right)-\sigma^{K E}\left(1-\theta_{K M}\right)\left(1-\theta_{K}\right)-\sigma^{K E L}\left(1-\theta_{K M}\right) \theta_{K}\left(1-\theta_{K E}\right)
$$

where 


\begin{tabular}{lcc}
\hline \hline Product category & Germany & Mean \\
\hline Food & -.222 & -.220 \\
Clothing & -.423 & -.422 \\
Housing & -.426 & -.432 \\
Durable consumption goods & -.501 & -.585 \\
Health & -.844 & -.734 \\
Traffic & -.591 & -.665 \\
Recreation & -.608 & -.628 \\
Other & -.547 & -.605 \\
\hline \hline
\end{tabular}

Table 3: Price elasticities of consumption demand

$\sigma^{K} \quad:=$ elasticity of substitution between domestic and foreign capital,

$\theta_{K M}:=$ share of capital imports in domestic capital use,

$\theta_{K}:=$ share of capital in the capital-energy sub-aggregate,

$\theta_{K E}:=$ share of $\mathrm{KE}$ in the capital-energy-labour sub-aggregate, and elasticities of substitution, $\sigma$, like in Figure 1.

We calibrate $\sigma^{K}$ to match values of the capital import ratio (one minus the "domestic ownership share"), $\theta_{K M}=0.18$ (French and Poterba, 1991), and the elasticity of capital imports with respect to the domestic interest rate $\varepsilon_{K M}=2.4$ (de Mooij and Ederveen, 2001).

The elasticity of capital exports with respect to the domestic interest rate can be computed from the constant-elasticity-of-transformation function, splitting up domestic savings into capital exports and domestically used capital. Here we have:

$$
\varepsilon_{K X}=-\eta^{K S}\left(1-\theta_{K X}\right)
$$

where

$\eta^{K S}:=$ elasticity of transformation $\left(1-\sigma^{K S}\right)$ between capital exports and domestically used capital,

$\theta_{K X}:=$ share of capital exports in domestic savings.

$\eta^{K S}$ is calibrated to values of the capital export ratio (one minus the "domestic equity share"), $\theta_{K X}=0.21$ (French and Poterba, 1991), and the elasticity of capital exports with respect to the domestic interest rate $\varepsilon_{K X}=-2.4$ (de Mooij and Ederveen, 2001). 


\section{Simulations}

In our simulations of revenue-neutral VAT reforms for the German economy we replace the differentiated VAT rate by a uniform rate (while the treatment of taxexempt goods remains unchanged). Regarding the use of the additional revenues we employ alternative assumptions. Basically, we distinguish two variants. In the first variant of a pure VAT reform, we introduce a uniform VAT rate at a level which keeps revenue constant. In the second variant, the rate for commodities with lower VAT is set at the normal level. This implies that revenues from VAT increase, and we balance the public budget through uniform adjustments of income taxes or social security contributions. In addition to simulations with uniform adjustment of the compensating source of revenue across households, we carry out simulations with non-uniform adjustments such that not only revenue-neutrality but also distributive neutrality is warranted.

\subsection{Distributive Effects and Efficiency}

Our discussion of simulation results starts with a scenario in which the differentiated VAT (16\% and $7 \%$, respectively) is replaced in a revenue-neutral way by a uniform VAT rate at an intermediate level (Scenario 1). Taking general equilibrium repercussions into account, the level of the post-reform VAT amounts to $14.1 \%$ (as compared to $16 \%$ normal VAT rate before).

The redistributive effects of this pure VAT reform are reported in Table 4 both in terms of equivalent variation in percent of the benchmark income and in terms of absolute changes. Reflecting the higher share of goods with a reduced VAT rate in the expenditures of the lowest tercile (see Table 2), Scenario 1 has some adverse distributional effects. However, these redistributive effects of switching to a uniform VAT are very small. We furthermore see that the gain for the upper tercile - while lower than the loss of the lower tercile in relative terms - is higher in absolute terms.

\begin{tabular}{lccc}
\hline \hline Scenario 1 & lower tercile & middle tercile & upper tercile \\
\hline EV in per cent & -0.24 & +0.00 & +0.18 \\
EV in $€$ per month & -5.8 & +0.1 & +16.6 \\
\hline \hline
\end{tabular}

Table 4: Pure VAT reform 
Next, we analyse different varieties of tax reforms that use other tax recycling instruments than the VAT itself for balancing the public budget. In Scenario 2, we uniformly (in percentage points) cut the marginal income tax rate (MITR) to warrant revenue neutrality.

\begin{tabular}{lccc}
\hline \hline Scenario 2 & lower tercile & middle tercile & upper tercile \\
\hline pre-reform MITR & $14.9 \%$ & $16.1 \%$ & $22.1 \%$ \\
post-reform MITR & $14.1 \%$ & $15.3 \%$ & $21.3 \%$ \\
EV in per cent & -0.62 & -0.02 & +0.39 \\
EV in € per month & -15.1 & -0.8 & +35.9 \\
\hline \hline
\end{tabular}

Table 5: Uniform cut in MITR

Table 5 indicates that the distributional effects are larger than for the case of a pure VAT reform. While the middle tercile is still virtually unaffected by the reform, the losses for the lower tercile and the gains for the upper tercile are more than double the respective figures of Scenario 1. Uniform cuts in the marginal income tax rate are favourable for the upper tercile because taxable income makes up the largest fraction of total income in this tercile.

In Scenario 3, we maintain the marginal income tax as the recycling instrument for balancing the public budget, but impose the restriction of distributive neutrality. The marginal income tax rate (MITR) is now endogenously adjusted so that the percentage change in EV is the same across all households. Table 6 summarises the implications of this (non-uniform) adjustment rule.

\begin{tabular}{lccc}
\hline \hline Scenario 3 & lower tercile & middle tercile & upper tercile \\
\hline pre-reform MITR & $14.9 \%$ & $16.1 \%$ & $22.1 \%$ \\
post-reform MITR & $12.6 \%$ & $15.2 \%$ & $21.6 \%$ \\
EV in per cent & +0.12 & +0.12 & +0.12 \\
EV in € per month & +2.9 & +5.2 & +10.9 \\
\hline \hline
\end{tabular}

Table 6: Redistributively neutral cut in MITR

The tax reduction of the MITR (in terms of the tax rate) is highest for the lower tercile $(-2.3$ p.p.) and lowest for the upper tercile $(-0.5$ p.p.). This results in a uniform increase in the equivalent variation of $0.12 \%$.

Tax revenue recycling through the income tax may alternatively be based on the income tax allowance (ITA). Table 7 reports scenario results for the case of a uniform 
increase (in $€$ ) of the tax allowance for all households (Scenario 4).

\begin{tabular}{lccc}
\hline \hline Scenario 4 & lower tercile & middle tercile & upper tercile \\
\hline pre-reform ITA in $€$ & 247 & 417 & 1127 \\
post-reform ITA in $€$ & 260 & 430 & 1140 \\
EV in per cent & -0.10 & -0.10 & -0.12 \\
EV in $€$ per month & -2.5 & -4.2 & -11.7 \\
\hline \hline
\end{tabular}

Table 7: Uniform increase in ITA

In this scenario, all households face welfare losses, reflecting the implied increase in the marginal tax burden. Moreover, the losses are almost identical across terciles. This latter result can be explained by two countervailing effects that more or less cancel each other out. On the one hand, a given increase of the ITA in $€$ means a lower relative increase for the upper terciles. On the other hand, the upper terciles have higher marginal income tax rates, so that they benefit more from a given relative increase in the tax allowance.

The policy settings for Scenario 5 differ from those of Scenario 4 only in that tax allowances are differentiated endogenously in order to yield proportional welfare changes across all households. Distributional results are provided in Table 8. As Scenario 4 was almost distributionally neutral, the results for Scenario 5 are very much alike.

\begin{tabular}{lccc}
\hline \hline Scenario 5 & lower tercile & middle tercile & upper tercile \\
\hline pre-reform ITA in $€$ & 247 & 417 & 1127 \\
post-reform ITA in $€$ & 261 & 430 & 1140 \\
EV in per cent & -0.11 & -0.11 & -0.11 \\
EV in $€$ per month & -2.8 & -4.9 & -10.4 \\
\hline \hline
\end{tabular}

Table 8: Redistributively neutral increase in ITA

Given distributional neutrality for Scenarios 3 and 5, both scenarios can be compared in efficiency terms. We can then see that Scenario 5 induces (small) welfare losses, while Scenario 3 leads to (small) efficiency gains. The reasoning behind this is that in Scenario 5 we essentially replace a lumpsum tax by a distortive tax, whereas in Scenario 3 we trade off two distortive taxes against each other.

The third instrument of tax revenue recycling considered in our analysis are the social security contributions (SSC). Again, we first show the case where the SSC are 
changed uniformly (Scenario 6), and then differentiate the SSC of the households endogenously to achieve proportional welfare gains across households (Scenario 7).

\begin{tabular}{lccc}
\hline \hline Scenario 6 & lower tercile & middle tercile & upper tercile \\
\hline pre-reform SSC & $23.5 \%$ & $20.4 \%$ & $12.7 \%$ \\
post-reform SSC & $21.3 \%$ & $18.4 \%$ & $11.4 \%$ \\
EV in per cent & -0.26 & +0.34 & +0.30 \\
EV in $€$ per month & -6.3 & +14.9 & +27.7 \\
\hline \hline
\end{tabular}

Table 9: Uniform cut in SSC

A uniform proportional decrease of the SSC - as in Table 9 - leaves the middle tercile substantially better off. The welfare gain for the upper tercile is also significant, whereas the lower tercile clearly loses. The fact that the middle tercile benefits most is explained by the highest share of labour income (the tax base for the SSC) in this group. In contrast, for the lower tercile, transfer income makes up a large part of total income, and for the upper tercile capital income gains in weight.

\begin{tabular}{lccc}
\hline \hline Scenario 7 & lower tercile & middle tercile & upper tercile \\
\hline pre-reform SSC & $23.5 \%$ & $20.4 \%$ & $12.7 \%$ \\
post-reform SSC & $20.0 \%$ & $18.7 \%$ & $11.6 \%$ \\
EV in per cent & +0.21 & +0.21 & +0.21 \\
EV in € per month & +5.1 & +9.0 & +18.9 \\
\hline \hline
\end{tabular}

Table 10: Redistributively neutral cut in SSC

When we adjust the SSC in a way that assures distributive neutrality (see Table 10), the cut in SSC is highest for the lower tercile ( -3.5 p.p.) and lowest for the upper tercile $(-1.1$ p.p.). In relative terms, the cut is now lowest for the middle tercile (to compensate for its high share of labour income). The uniform welfare increase amounts to $0.21 \%$, which stands out as the highest value across all scenarios and makes the SSC the most attractive candidate for actual tax reforms. Our results indicate that the distortive effects of the SSC are higher than those of the MITR, which in turn means that distortive effects of labour taxation outweigh those of capital income taxation. 


\subsection{Macroeconomic Effects}

Table 11 summarises the macroeconomic consequences across four of our scenarios: the pure VAT reform (Scenario 1) and the three scenarios based on alternative tax recycling instruments (Scenarios 3,5 and 7) where distributional effects are compensated.

\begin{tabular}{lcccc}
\hline \hline Scenario & 1 & 3 & 5 & 7 \\
Tax recycling instrument & VAT & MITR & ITA & SSC \\
\hline GDP & 0.11 & 0.36 & -0.10 & 0.45 \\
Employment & 0.02 & 0.14 & -0.25 & 0.36 \\
Domestic capital use & 0.25 & 0.68 & 0.10 & 0.57 \\
Total consumption & 0.08 & 0.26 & -0.30 & 0.49 \\
Imports & -0.32 & -0.26 & -0.64 & -0.05 \\
Exports & -0.03 & 0.47 & -0.47 & 0.54 \\
\hline \hline
\end{tabular}

Table entries are given as percentage changes.

Table 11: Macroeconomic Effects of VAT reform

Table 11 confirms the ranking of the tax recycling instruments that we already deduced from the EV values in Section 3.1. The SSC are the most favourable tax recycling instrument, followed by the MITR, the VAT itself, and the ITA at the bottom of the ranking. The same ranking holds with respect to key economic indicators such as GDP, employment, domestic capital use, aggregate consumption, or exports.

\subsection{Industry Effects}

Table 12 reports the impacts of VAT reforms on the output of individual industries. We condense the information on the 69 sectors of the model into a few aggregate indicators: the average (unweighted) sectoral output growth and its standard deviation, the number of growing and shrinking industries, maximum and minimum of the industries' growth rates as well as the 10th and 90th percentile.

The figures in Table 12 confirm our previous ranking of the tax recycling instruments. Around the average values, there is a considerable spread in the industry-level outcomes. This spread is rather robust across the scenarios. At the disaggregated industry-level, the performance across sectors is also rather stable: Financial and 


\begin{tabular}{lcccc}
\hline \hline Scenario & 1 & 3 & 5 & 7 \\
Tax recycling instrument & VAT & MITR & ITA & SSC \\
\hline Av. increase in industries' production & 0.10 & 0.46 & -0.21 & 0.48 \\
$\quad$ Standard deviation & 1.08 & 1.18 & 1.17 & 1.06 \\
Number of growing industries & 32 & 48 & 19 & 56 \\
Number of shrinking industries & 37 & 21 & 50 & 13 \\
Maximum growth & 5.45 & 5.66 & 5.38 & 5.60 \\
Minimum growth & -2.02 & -1.61 & -2.82 & -1.05 \\
90th percentile & 0.56 & 1.38 & 0.41 & 0.91 \\
10th percentile & -0.59 & -0.26 & -1.01 & -0.18 \\
\hline \hline
\end{tabular}

Entries are changes in percent (except number of growing/shrinking industries).

Table 12: Sectoral effects

Insurance services as well as Research and Development are always among the industries that gain the most, whereas Communication and Media, Other Vehicles and Hotel and Catering Industry show the largest losses.

\subsection{Sensitivity Analysis}

The fact that SSC is more advantageous as a tax recycling instrument than MITR indicates that the taxation of labour is more distorting than the taxation of capital. However, if capital were more mobile, internationally, than assumed in the simulations, the distortionary effects of capital taxation increase and the MITR might be expected to perform relatively better as a tax recycling instrument. Since the degree of capital mobility is subject to controversial debates, we single out the elasticities of international capital mobility as the model parameters for a more detailed sensitivity analysis: We double the values of the international capital mobility elasticities (capital import and export elasticities).

Table 13 shows that the ranking of the scenarios does not change as compared to the base case. ${ }^{5} \mathrm{SSC}$ (Scenario $7 \mathrm{~s}$ ) remain the most advantageous tax recycling instrument. As expected, the difference between Scenarios 3 and 7 (MITR and SSC as tax recycling instruments) decreases with increasing capital mobility - however, this reduction is rather small even for the assumed doubling of elasticities. This

\footnotetext{
${ }^{5}$ Table 13 is augmented by a row "Welfare (EV)" to be compared with the respective entries in Tables 6, 8 and 10 in Section 3.1.
} 


\begin{tabular}{lcccc}
\hline \hline Scenario & $1 \mathrm{~s}$ & $3 \mathrm{~s}$ & $5 \mathrm{~s}$ & $7 \mathrm{~s}$ \\
Tax recycling instrument & VAT & MITR & ITA & SSC \\
\hline Welfare (EV) & & 0.16 & -0.11 & 0.24 \\
GDP & 0.15 & 0.46 & -0.09 & 0.53 \\
Employment & 0.03 & 0.19 & -0.25 & 0.41 \\
Domestic capital use & 0.30 & 0.85 & 0.12 & 0.70 \\
Total consumption & 0.11 & 0.34 & -0.29 & 0.57 \\
Imports & -0.31 & -0.22 & -0.64 & -0.01 \\
Exports & -0.04 & 0.70 & -0.45 & 0.71 \\
\hline \hline
\end{tabular}

Table entries are given as percentage changes.

Table 13: Macroeconomic Effects

indicates that the MITR can become a serious competitor of the SSC only for degrees of international capital mobility that are far above empirically reported values (see e.g. de Mooij and Ederveen, 2001).

\section{Conclusions}

In this paper, we have investigated the economic effects of VAT reform for the German economy. Based on an AGE framework tailored to the requirements of VAT reform analysis, we have simulated several revenue-neutral variants of abolishing the reduced VAT rate in Germany. We have compared a pure VAT reform, where the differentiated VAT is replaced with a uniform rate, and scenarios in which tax revenue is recycled through other taxes: the marginal income tax rate (MITR), the income tax allowance (ITA) or the social security contributions (SSC).

Our main findings can be summarised as follows: The abolition of the reduced VAT rate in itself has only a small redistributive effect towards more inequality. Therefore, VAT differentiation can hardly be considered as a suitable means of redistribution policy. When we combine the abolition of reduced VAT rates with revenue recycling through reduction of the marginal income tax rate or cuts in social security contributions, there is scope for significant gains in overall welfare. The income tax allowance, in contrast, produces welfare losses if used as a tax recycling instrument. Policy-induced changes in macroeconomic indicators like GDP, employment, domestic capital use, or aggregate consumption echo the welfare ranking of tax instruments. While the distributional effects of VAT reforms are within a relatively 
narrow range, the sectoral effects (in terms of variation in sectoral output) are much more pronounced. This indicates that the VAT rate differentiation should be viewed primarily as a sectoral subsidy rather than an instrument of redistribution. From a political economy point of view, the sectoral implications highlight lobbying interests of adversely affected sectors to work against changes of the actual VAT structure.

\section{References}

[1] Atkinson, Anthony B., Lee Rainwater and Timothy M. Smeeding (1995): Income distribution in OECD Countries: Evidence from the Luxembourg Income Study (LIS), OECD Social Policy Studies No. 18, Paris.

[2] Åvitsland, Turid, and Jørgen Aasness (2004): Combining CGE and microsimulation models: Effects on equality of VAT reforms, Statistics Norway, Discussion Paper No. 392.

[3] Ballard, Charles L., John Karl Scholz, and John B. Shoven (1987): The valueadded tax: A general equilibrium look at its efficiency and incidence, in: Feldstein, Martin (ed.): The effects of taxation on capital accumulation, Chicago: University of Chicago Press, 445-474.

[4] Biewen, Martin (2000): Income inequality in Germany during the 1980s and 1990s, Review of Income and Wealth, 46, 1-19.

[5] Böhringer, Christoph, Stefan Boeters, and Michael Feil (2005): Taxation and unemployment: An applied general equilibrium approach for Germany, Economic Modelling 22, 81-108.

[6] Böhringer, Christoph, and Andreas Lange (2005): Economic implications of alternative allocation schemes for emission allowances, Scandinavian Journal of Economics 107, 563-581.

[7] Borjas, George J. (2000): Labor economics, 2nd ed., Boston, MA: McGraw-Hill.

[8] Chen, Dongling L. (1999): World consumption economics, Singapore.

[9] De Mooij, Ruud A., and Sjef Ederveen (2001): Taxation and foreign direct investment, a synthesis of empirical research, CPB Netherlands Bureau for Economic Policy Analysis, Discussion Paper No. 003. 
[10] Dixon, Peter B., and Maureen T. Rimmer (1999): Changes in indirect taxes in Australia: A dynamic general equilibrium analysis, Australian Economic Review, 32, 327-48.

[11] European Commission (2005): VAT rates applied in the member states of the European Community, DOC/1636/2005-EN, Brussels.

[12] French, Kenneth R and James M. Poterba (1991): Investor diversification and international equity markets, American Economic Review, 81, 222-226.

[13] Gottfried, Peter, and Wolfgang Wiegard (1991): Exemption versus zero rating. A hidden problem of VAT, Journal of Public Economics, 46, 307-328.

[14] Hamilton, Bob, and John Whalley (1989): Reforming indirect taxes in Canada: some general equilibrium estimates, Canadian Journal of Economics, 22, 561575 .

[15] Keen, Michael and Jack Mintz (2004): The optimal threshold for a value added tax, Journal of Public Economics, 88, 559-576.

[16] Koskela, Erkki and Jouko Vilmunen (1996): Tax progression is good for employment in popular models of trade union behaviour, Labour Economics 3, 65-80.

[17] Theil, Henry (1980): The system-wide approach to microeconomics, Chicago. 


\section{Appendix: Model Description}

In this appendix we give a full algebraic description of the model. A list of all sets, indices, variables and parameters can be found in Sections I.1 to I.3. Section I.4 then presents the equations, classified into price and demand equations, market clearance conditions and household budget constraints.

\section{I.1 Indices and Index Sets}

\section{I.1.1 Sets}

$c \quad:=$ consumption good index

$h \quad:=$ household index

$i \quad:=$ general index

$s, s s \quad:=$ sectoral indices

$s g \quad:=$ index for skill groups (high, low skilled)

\section{I.1.2 Index Sets}

$C \quad:=$ all 12 consumption good categories

$E L E \quad:=$ one-element set: electricity

$F \quad:=$ one-element set: food consumption

$F E N \quad:=$ fossil energy sectors

$N E N:=$ non-energy sectors

$N F \quad:=$ non-food consumption goods

$S \quad:=$ all 69 sectors of the German IOT 1997

$V A T:=$ different VAT rates

\section{I.2 Variables}

\section{I.2.1 Quantities}

$A_{s}:=$ Armington good

$A_{s, c}:=$ intermediate inputs for consumption (Z-matrix)

$A_{s, G}:=$ intermediate input for government consumption

$A_{s, I}:=$ intermediate input for investment goods 


$\begin{array}{lll}A_{s, s s} & :=\text { intermediate inputs for production } \\ A_{s, S T K} & :=\text { stock changes } \\ C_{c} & :=\text { consumption goods } \\ C_{c, h} & :=\text { consumption goods by household } \\ C_{c, h, V A T} & :=\text { consumption goods by VAT category } \\ C_{h} & :=\text { consumption good aggregate } \\ D_{s} & :=\text { deliveries to the domestic market } \\ E_{c} & :=\text { energy aggregate in consumption } \\ E_{s} & :=\text { energy aggregate in production } \\ F E_{c} & :=\text { fossil energy aggregate in consumption } \\ F E_{s} & :=\text { fossil energy aggregate in production } \\ G & :=\text { government consumption } \\ I & :=\text { aggregate investment } \\ I_{G} & :=\text { government investment } \\ K & :=\text { total capital employed domestically } \\ K_{s} & :=\text { capital input } \\ K D & :=\text { domestically invested capital } \\ K D_{h} & :=\text { domestically invested capital by household } \\ K E_{s} & :=\text { capital-energy aggregate in production } \\ K E L_{s} & :=\text { quantity of capital-energy-labour aggregate } \\ K M & :=\text { capital imports } \\ K X_{h} & :=\text { capital exports } \\ L_{s, s g} & :=\text { labour input by skill group } \\ L E_{h} & :=\text { leisure aggregate } \\ L E_{h, s g} & :=\text { leisure by skill group } \\ M_{s} & :=\text { imports } \\ N F_{h} & :=\text { non-food consumption } \\ U_{h} & :=\text { utility index } \\ X_{s} & :=\text { Exports } \\ Y_{s} & :=\text { production in sector } s \\ & :=1\end{array}$

\section{I.2.2 Prices}

$p_{A, s}:=$ price of Armington commodity

$p_{c}:=$ price of consumption goods (gross of VAT)

$p_{C, h}:=$ price of consumption goods aggregate 


$$
\begin{array}{lll}
p_{p, c} & :=\text { production price of consumption good } \\
p_{D, s} & :=\text { price of output delivered to the domestic market } \\
p_{E, c} & :=\text { price of energy aggregate in consumption } \\
p_{E, s} & :=\text { price of energy aggregate in production } \\
p_{F} & :=\text { price of food consumption } \\
p_{G} & :=\text { price index of government consumption } \\
p_{F E, c} & :=\text { price of fossil energy aggregate in consumption } \\
p_{F E, s} & :=\text { price of fossil energy aggregate in production } \\
p_{I} & :=\text { price index for investment goods } \\
p_{K} & :=\text { rental rate of capital } \\
p_{K E, s} & :=\text { price of the capital-energy aggregate } \\
p_{K E L, s} & :=\text { price of the capital-energy-labour aggregate } \\
p_{K D} & :=\text { price of capital in the domestic market } \\
p_{K M} & :=\text { price of capital imports } \\
p_{K S, h} & :=\text { price for capital supply of households } \\
p_{K X} & :=\text { price of capital exports } \\
p_{L, s g} & :=\text { wage (net of payroll tax) by skill group } \\
p_{L E, h} & :=\text { price index for leisure } \\
p_{L E, h, s g} & :=\text { price index for leisure, by skill group } \\
p_{L S, h, s g} & :=\text { expected revenue from labour supply } \\
p_{M, s} & :=\text { import prices (net of import tax) } \\
p_{N F, h} & :=\text { price of non-food aggregate consumption } \\
p_{U, h} & :=\text { price of utility aggregate (expenditure function) } \\
p_{X, s} & :=\text { export prices } \\
p_{Y, s} & :=\text { producer prices }
\end{array}
$$

\section{I.2.3 Others}

$$
\begin{aligned}
& u_{s g}:=\text { unemployment rate } \\
& Y_{h}:=\text { extended income of households }
\end{aligned}
$$

\section{I.3 Parameters}

\section{I.3.1 Value Shares}

$\theta^{i}:=$ value share of item $i$ in its respective sub-aggregate in the benchmark 


\section{I.3.2 Taxes}

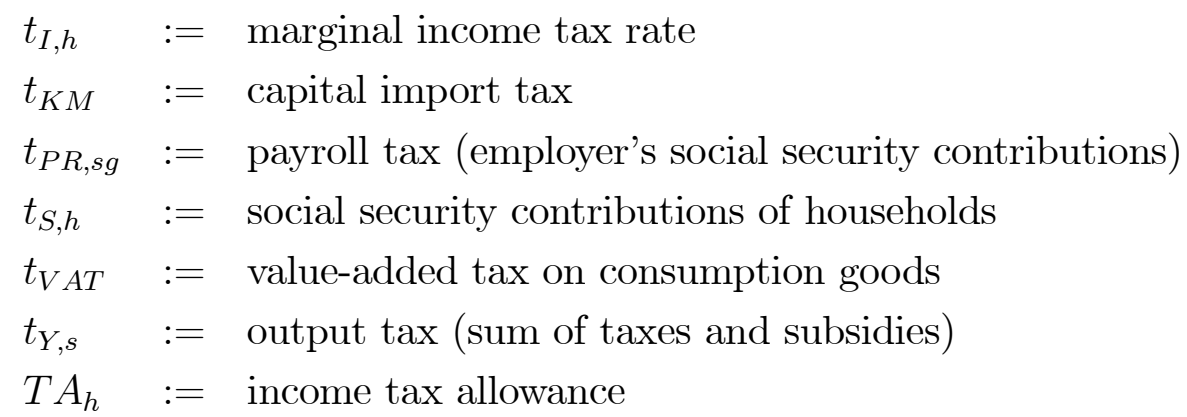

\section{I.3.3 Elasticities}

$\sigma_{s}^{A} \quad:=$ EOS between domestic production and imports

$\sigma_{h}^{C} \quad:=$ EOS between food and non-food consumption

$\sigma_{c}^{E} \quad:=$ EOS between electricity and fossil fuels

$\sigma_{s}^{E} \quad:=$ EOS between electricity and fossil fuels

$\sigma_{c}^{F E}:=$ EOS between varieties of fossil fuels

$\sigma_{s}^{F E}:=$ EOS between varieties of fossil fuels

$\sigma^{K} \quad:=$ EOS between domestic capital and capital imports

$\sigma_{s}^{K E}:=$ EOS between $\mathrm{K}$ and $\mathrm{E}$

$\sigma_{s}^{K E L}:=$ EOS between $\mathrm{KE}$ and $\mathrm{L}$

$\sigma^{K S}:=$ EOS between domestic and foreign investment

$\sigma_{h}^{L E}:=$ EOS between leisure of different skill types

$\sigma_{c}^{N E}:=$ EOS between NEN goods in consumption

$\sigma_{h}^{N F}:=$ EOS between non-food goods

$\sigma_{s}^{T} \quad:=$ EOT between domestic use and exports

$\sigma_{h}^{U} \quad:=$ EOS between leisure and consumption

$\sigma_{c}^{V A T}:=$ EOS between good varieties with different VAT rate 1.0

$\sigma_{s}^{Y} \quad:=$ EOS between intermediate inputs and KEL aggregate 0.0

$\sigma_{h}^{U}$ and $\sigma_{h}^{L E}$ are calibrated to reproduce empirical labour supply elasticities. $\sigma^{K}$ and $\sigma^{K S}$ are calibrated to reproduce capital import and export elasticities. $\sigma_{h}^{C}$ and $\sigma_{h}^{N F}$ are calibrated to reproduce consumption good demand elasticities. The calibration procedures are explained in Sections 2.3.2 and 2.3.3 of the main text. 


\section{I.3.4 Others}

$b \quad:=$ unemployment benefits

$\overline{B O P}:=$ balance of payments surplus

$\bar{I}_{h} \quad:=$ savings $=$ investment by household

$\bar{K}_{h} \quad:=$ capital endowment by household

$\bar{L}_{h, s g}:=$ time endowment by household

$\overline{T R}_{h}:=$ benchmark transfers

Any variable (or parameter in the case of taxes) with an upper bar denotes its benchmark value.

\section{I.4 Model Equations}

The model equations are split up into price and demand equations, market clearance conditions, budget constraints and auxiliary equations. There are no explicit production functions in the model, because all necessary information is contained in the dual price functions.

To maintain structural symmetry, the equations are written down in their most general form. In the actual numerical implementation of the model, considerable simplifications are achieved by normalising benchmark prices and quantities to unity where possible. Some of the CES functions collapse to Cobb-Douglas or Leontief functions by setting the elasticity of substitution to one or zero, respectively (see Section I.3.3).

\section{I.4.1 Price Equations}

Production is organised according to a nested CES production function. Subsets of sectoral inputs that are used to form sub-nests of the productions function can be found in Section I.1.1.

$$
\begin{gathered}
\frac{p_{Y, s}\left(1-t_{Y, s}\right)}{\bar{p}_{Y, s}\left(1-\bar{t}_{Y, s}\right)}=\left[\theta_{s}^{K E L}\left(\frac{p_{K E L, s}}{\bar{p}_{K E L, s}}\right)^{1-\sigma_{s}^{Y}}+\sum_{s s \in N E N} \theta_{s}^{s s}\left(\frac{p_{A, s s}}{\bar{p}_{A, s s}}\right)^{1-\sigma_{s}^{Y}}\right]^{\frac{1}{1-\sigma_{s}^{Y}}} \\
\frac{p_{K E L, s}}{\bar{p}_{K E L, s}}=\left[\theta_{s}^{K E}\left(\frac{p_{K E, s}}{\bar{p}_{K E, s}}\right)^{1-\sigma_{s}^{K E L}}+\sum_{s g} \theta_{s}^{s g}\left(\frac{p_{L, s g}\left(1+t_{P R, s g}\right)}{\bar{p}_{L, s g}\left(1+\bar{t}_{P R, s g}\right)}\right)^{1-\sigma_{s}^{K E L}}\right]^{\frac{1}{1-\sigma_{s}^{K E L}}}
\end{gathered}
$$




$$
\begin{gathered}
\frac{p_{K E, s}}{\bar{p}_{K E, s}}=\left[\theta_{s}^{K}\left(\frac{p_{K}}{\bar{p}_{K}}\right)^{1-\sigma_{s}^{K E}}+\theta_{s}^{E}\left(\frac{p_{E, s}}{\bar{p}_{E, s}}\right)^{1-\sigma_{s}^{K E}}\right]^{\frac{1}{1-\sigma_{s}^{K E}}} \\
\frac{p_{E, s}}{\bar{p}_{E, s}}=\left[\theta_{s}^{E L E}\left(\frac{p_{A, E L E}}{\bar{p}_{A, E L E}}\right)^{1-\sigma_{s}^{E}}+\theta_{s}^{F E C}\left(\frac{p_{F E, s}}{\bar{p}_{F E, s}}\right)^{1-\sigma_{s}^{E}}\right]^{\frac{1}{1-\sigma_{s}^{E}}} \\
\frac{p_{F E, s}}{\bar{p}_{F E, s}}=\left[\sum_{i \in F E N} \theta_{s}^{i}\left(\frac{p_{A, i}}{\bar{p}_{A, i}}\right)^{1-\sigma_{s}^{F E}}\right]^{\frac{1}{1-\sigma_{s}^{F E}}}
\end{gathered}
$$

Output is split into domestic use and exports through a CET function:

$$
\frac{p_{Y, s}}{\bar{p}_{Y, s}}=\left[\theta_{s}^{D Y}\left(\frac{p_{D, s}}{\bar{p}_{D, s}}\right)^{1+\sigma_{s}^{T}}+\theta_{s}^{X}\left(\frac{p_{X, s}}{\bar{p}_{X, s}}\right)^{1+\sigma_{s}^{T}}\right]^{\frac{1}{1+\sigma_{s}^{T}}}
$$

Domestically produced goods and imports are combined to an "Armington good":

$$
\frac{p_{A, s}}{\bar{p}_{A, s}}=\left[\theta_{s}^{D A}\left(\frac{p_{D, s}}{\bar{p}_{D, s}}\right)^{1-\sigma_{s}^{A}}+\theta_{s}^{M}\left(\frac{p_{M, s}\left(1+t_{M, s}\right)}{\bar{p}_{M, s}\left(1+\bar{t}_{M, s}\right)}\right)^{1-\sigma_{s}^{A}}\right]^{\frac{1}{1-\sigma_{s}^{A}}}
$$

Household utility is derived from consumption of goods and leisure:

$$
\begin{gathered}
\frac{p_{U, h}}{\bar{p}_{U, h}}=\left[\theta_{h}^{C}\left(\frac{p_{C, h}}{\bar{p}_{C, h}}\right)^{1-\sigma_{h}^{U}}+\theta_{h}^{L E}\left(\frac{p_{L E, h}}{\bar{p}_{L E, h}}\right)^{1-\sigma_{h}^{U}}\right]^{\frac{1}{1-\sigma_{h}^{U}}} \\
\frac{p_{C, h}}{\bar{p}_{C, h}}=\left[\theta_{h}^{F}\left(\frac{p_{F}}{\bar{p}_{F}}\right)^{1-\sigma_{h}^{C}}+\theta_{h}^{N F}\left(\frac{p_{N F, h}}{\bar{p}_{N F, h}}\right)^{1-\sigma_{h}^{C}}\right]^{\frac{1}{1+\sigma_{h}^{C}}} \\
\left.\frac{p_{N F, h}}{\bar{p}_{N F, h}}=\left[\sum_{c \in N F} \theta_{h}^{c}\left(\frac{p_{c}}{\bar{p}_{c}}\right)^{1-\sigma_{h}^{N F}}\right]^{\frac{1}{1-\sigma_{h}^{N F}}}\right]^{p_{c}}=\left[\sum_{V A T} \theta^{c, V A T}\left(\frac{p_{p, c}\left(1+t_{V A T}\right)}{\bar{p}_{p, c}\left(1+\bar{t}_{V A T}\right)}\right)^{1-\sigma_{c}^{V A T}}\right]^{\frac{1}{1-\sigma_{c}^{V A T}}} \text { for } c \in F, N F \\
\frac{p_{L E, h}}{\bar{p}_{L E, h}}=\left[\sum_{s g \in S G} \theta_{h}^{s g}\left(\frac{p_{L E, h, s g}}{\bar{p}_{L E, h, s g}}\right)^{1-\sigma_{h}^{L E}}\right]^{\frac{1}{1-\sigma_{h}^{L E}}}
\end{gathered}
$$

Consumption goods are produced from the output of the production sectors with a CES production function:

$$
\frac{p_{p, c}}{\bar{p}_{p, c}}=\left[\sum_{s \in N E N} \theta_{c}^{s}\left(\frac{p_{A, s}}{\bar{p}_{A, s}}\right)^{1-\sigma_{c}^{N E}}+\theta_{c}^{E}\left(\frac{p_{E, c}}{\bar{p}_{E, c}}\right)^{1-\sigma_{c}^{N E}}\right]^{\frac{1}{1-\sigma_{c}^{N E}}}
$$




$$
\begin{gathered}
\frac{p_{E, c}}{\bar{p}_{E, c}}=\left[\theta_{c}^{E L E}\left(\frac{p_{A, E L E}}{\bar{p}_{A, E L E}}\right)^{1-\sigma_{c}^{E}}+\theta_{c}^{F E}\left(\frac{p_{F E, c}}{\bar{p}_{F E, c}}\right)^{1-\sigma_{c}^{E}}\right]^{\frac{1}{1-\sigma_{c}^{E}}} \\
\frac{p_{F E, c}}{\bar{p}_{F E, c}}=\left[\sum_{s \in F E N} \theta_{c}^{s}\left(\frac{p_{A, s}}{\bar{p}_{A, s}}\right)^{1-\sigma_{c}^{F E}}\right]^{\frac{1}{1-\sigma_{c}^{F E}}}
\end{gathered}
$$

Government demand is composed of government investment and inputs from the production sectors in fixed proportions:

$$
\frac{p_{G}}{\bar{p}_{G}}=\theta_{G}^{I} \frac{p_{I}}{\bar{p}_{I}}+\sum_{s} \theta_{G}^{s} \frac{p_{A, s}}{\bar{p}_{A, s}}
$$

Investment goods are also produced with fixed production coefficients:

$$
\frac{p_{I}}{\bar{p}_{I}}=\sum_{s} \theta_{I}^{s} \frac{p_{A, s}}{\bar{p}_{A, s}}
$$

Capital supply is transformed into domestic use and capital exports through a CET function:

$$
\frac{p_{K S, h}}{\bar{p}_{K S, h}}=\left[\theta^{K D}\left(\frac{p_{K D}\left(1-t_{I, h}\right)}{\bar{p}_{K D}\left(1-\bar{t}_{I, h}\right)}\right)^{1+\sigma^{K S}}+\theta^{K X}\left(\frac{p_{K X}}{\bar{p}_{K X}}\right)^{1+\sigma^{K S}}\right]^{\frac{1}{1+\sigma^{K S}}}
$$

Domestic and imported capital are imperfect substitutes in production:

$$
\frac{p_{K}}{\bar{p}_{K}}=\left[\theta^{D K}\left(\frac{p_{K D}}{\bar{p}_{K D}}\right)^{1-\sigma^{K}}+\theta^{K M}\left(\frac{p_{K M}\left(1+t_{K M}\right)}{\bar{p}_{K M}\left(1+\bar{t}_{K M}\right)}\right)^{1-\sigma^{K}}\right]^{\frac{1}{1-\sigma^{K}}}
$$

\section{I.4.2 Demand and Supply Equations}

Demand for factors of production and intermediate inputs:

$$
\begin{aligned}
& \frac{A_{s s, s}}{\bar{A}_{s s, s}}=\frac{Y_{s}}{\bar{Y}_{s}}\left(\frac{p_{Y, s}\left(1-t_{Y, s}\right)}{\bar{p}_{Y, s}\left(1-\bar{t}_{Y, s}\right)} \frac{\bar{p}_{A, i}}{p_{A, i}}\right)^{\sigma_{s}^{Y}} \quad \text { for } \quad s s \in N E N \\
& \frac{K E L_{s}}{\overline{K E L}_{s}}=\frac{Y_{s}}{\bar{Y}_{s}}\left(\frac{p_{Y, s}\left(1-t_{Y, s}\right)}{\bar{p}_{Y, s}\left(1-\bar{t}_{Y, s}\right)} \frac{\bar{p}_{K E L, s}}{p_{K E L, s}}\right)^{\sigma_{s}^{Y}} \\
& \frac{L_{s, s g}}{\bar{L}_{s, s g}}=\frac{K E L_{s}}{\overline{K E L}_{s}}\left(\frac{p_{K E L, s}}{\bar{p}_{K E L, s}} \frac{\bar{p}_{L, s g}\left(1+\bar{t}_{P R, s g}\right)}{p_{L, s g}\left(1+t_{P R, s g}\right)}\right)^{\sigma_{s}^{K E L}} \\
& \frac{K E_{s}}{\overline{K E}_{s}}=\frac{K E L_{s}}{\overline{K E L}_{s}}\left(\frac{p_{K E L, s}}{\bar{p}_{K E L, s}} \frac{\bar{p}_{K E, s}}{p_{K E, s}}\right)^{\sigma_{s}^{K E L}}
\end{aligned}
$$




$$
\begin{gathered}
\frac{K_{s}}{\bar{K}_{s}}=\frac{K E_{s}}{\overline{K E}_{s}}\left(\frac{p_{K E, s}}{\bar{p}_{K E, s}} \frac{\bar{p}_{K}}{p_{K}}\right)^{\sigma_{s}^{K E}} \\
\frac{E_{s}}{\bar{E}_{s}}=\frac{K E_{s}}{\overline{K E}_{s}}\left(\frac{p_{K E, s}}{\bar{p}_{K E, s}} \frac{\bar{p}_{E, s}}{p_{E, s}}\right)^{\sigma_{s}^{K E}} \\
\frac{A_{E L E, s}}{\bar{A}_{E L E, s}}=\frac{E_{s}}{\bar{E}_{s}}\left(\frac{p_{E, s}}{\bar{p}_{E, s}} \frac{\bar{p}_{A, E L E}}{p_{A, E L E}}\right)^{\sigma_{s}^{E}} \\
\frac{F E_{s}}{\overline{F E}_{s}}=\frac{E_{s}}{\bar{E}_{s}}\left(\frac{p_{E, s}}{\bar{p}_{E, s}} \frac{\bar{p}_{F E, s}}{p_{F E, s}}\right)^{\sigma_{s}^{E}} \\
\left.\frac{F E_{s s, s}}{\bar{A}_{s s, s}}=\frac{p_{F E, s}}{\overline{F E}_{s}} \frac{\bar{p}_{A, s s}}{\bar{p}_{F E, s}}\right)^{\sigma_{s, s}^{F E}} \quad \text { for } \quad s s \in F E N
\end{gathered}
$$

Supply to the domestic and export market:

$$
\begin{aligned}
& \frac{D_{s}}{\bar{D}_{s}}=\frac{Y_{s}}{\bar{Y}_{s}}\left(\frac{\bar{p}_{Y, s}}{p_{Y, s}} \frac{p_{D, s}}{\bar{p}_{D, s}}\right)^{\sigma_{s}^{T}} \\
& \frac{X_{s}}{\bar{X}_{s}}=\frac{Y_{s}}{\bar{Y}_{s}}\left(\frac{\bar{p}_{Y, s}}{p_{Y, s}} \frac{p_{X, s}}{\bar{p}_{X, s}}\right)^{\sigma_{s}^{T}}
\end{aligned}
$$

Armington demands:

$$
\begin{gathered}
\frac{D_{s}}{\bar{D}_{s}}=\frac{A_{s}}{\bar{A}_{s}}\left(\frac{p_{A, s}}{\bar{p}_{A, s}} \frac{\bar{p}_{D, s}}{p_{D, s}}\right)^{\sigma_{s}^{A}} \\
\frac{M_{s}}{\bar{M}_{s}}=\frac{A_{s}}{\bar{A}_{s}}\left(\frac{p_{A, s}}{\bar{p}_{A, s}} \frac{\bar{p}_{M, s}\left(1+\bar{t}_{M, s}\right)}{p_{M, s}\left(1+t_{M, s}\right)}\right)^{\sigma_{s}^{A}}
\end{gathered}
$$

Household demand:

$$
\begin{aligned}
& \frac{C_{h}}{\bar{C}_{h}}=\frac{U_{h}}{\bar{U}_{h}}\left(\frac{p_{U, h}}{\bar{p}_{U, h}} \frac{\bar{p}_{C, h}}{p_{C, h}}\right)^{\sigma_{h}^{U}} \\
& \frac{L E_{h}}{\overline{L E}_{h}}=\frac{U_{h}}{\bar{U}_{h}}\left(\frac{p_{U, h}}{\bar{p}_{U, h}} \frac{\bar{p}_{L E, h}}{p_{L E, h}}\right)^{\sigma_{h}^{U}} \\
& \frac{C_{F, h}}{\bar{C}_{F, h}}=\frac{C_{h}}{\bar{C}_{h}}\left(\frac{p_{C, h}}{\bar{p}_{C, h}} \frac{\bar{p}_{F}}{p_{F}}\right)^{\sigma_{h}^{C}} \\
& \frac{N F_{h}}{\overline{N F}_{h}}=\frac{C_{h}}{\bar{C}_{h}}\left(\frac{p_{C, h}}{\bar{p}_{C, h}} \frac{\bar{p}_{N F, h}}{p_{N F, h}}\right)^{\sigma_{h}^{C}} \\
& \frac{C_{c, h}}{\bar{C}_{c, h}}=\frac{N F_{h}}{\overline{N F}_{h}}\left(\frac{p_{N F, h}}{\bar{p}_{N F, h}} \frac{\bar{p}_{c}}{p_{c}}\right)^{\sigma_{h}^{N F}} \quad \text { for } \quad c \in N F \\
& \frac{C_{c, h, V A T}}{\bar{C}_{c, h, V A T}}=\frac{C_{c, h}}{\bar{C}_{c, h}}\left(\frac{p_{c}}{\bar{p}_{c}} \frac{\bar{p}_{p, c}\left(1+\bar{t}_{V A T}\right)}{p_{p, c}\left(1+t_{V A T}\right)}\right)^{\sigma_{c}^{V A T}} \quad \text { for } \quad c \in F, N F
\end{aligned}
$$




$$
\frac{L E_{h, s g}}{\overline{L E}_{h, s g}}=\frac{L E_{h}}{\overline{L E}_{h}}\left(\frac{p_{L E, h}}{\bar{p}_{L E, h}} \frac{\bar{p}_{L E, h, s g}}{p_{L E, h, s g}}\right)^{\sigma_{h}^{L E}}
$$

Demand of production output for consumption goods:

$$
\begin{gathered}
\frac{A_{s, c}}{\bar{A}_{s, c}}=\frac{C_{c}}{\bar{C}_{c}}\left(\frac{p_{p, c}}{\bar{p}_{p, c}} \frac{\bar{p}_{A, s}}{p_{A, s}}\right)^{\sigma_{c}^{N E}} \text { for } s \in N E N \\
\frac{E_{c}}{\bar{E}_{c}}=\frac{C_{c}}{\bar{C}_{c}}\left(\frac{p_{p, c}}{\bar{p}_{p, c}} \frac{\bar{p}_{E, c}}{p_{E, c}}\right)^{\sigma_{c}^{N E}} \\
\frac{A_{E L E, c}}{\bar{A}_{E L E, c}}=\frac{E_{c}}{\bar{E}_{c}}\left(\frac{p_{E, c}}{\bar{p}_{E, c}} \frac{\bar{p}_{A, E L E}}{p_{A, E L E}}\right)^{\sigma_{c}^{E}} \\
\frac{F E_{c}}{\overline{F E}_{c}}=\frac{E_{c}}{\bar{E}_{c}}\left(\frac{p_{E, c}}{\bar{p}_{E, c}} \frac{\bar{p}_{F E, c}}{p_{F E, c}}\right)^{\sigma_{c}^{E}} \\
\frac{F E_{c, c}}{\bar{A}_{s, c}}=\frac{p_{F E, c}}{\overline{F E}_{c}}\left(\frac{\bar{p}_{A, s}}{\bar{p}_{F E, c}}\right)^{\sigma_{A, s}^{F E}} \quad \text { for } \quad s \in F E N
\end{gathered}
$$

Government demand:

$$
\frac{I_{G}}{\bar{I}_{G}}=\frac{A_{s, G}}{\bar{A}_{s, G}}=\frac{G}{\bar{G}}
$$

Demand for inputs for investment good production:

$$
\frac{A_{s, I}}{\bar{A}_{s, I}}=\frac{I}{\bar{I}}
$$

Demand for domestic and imported capital:

$$
\begin{gathered}
\frac{K D}{\overline{K D}}=\frac{K}{\bar{K}}\left(\frac{p_{K}}{\bar{p}_{K}} \frac{\bar{p}_{K D}}{p_{K D}}\right)^{\sigma^{K}} \\
\frac{K M}{\overline{K M}}=\frac{K}{\bar{K}}\left(\frac{p_{K}}{\bar{p}_{K}} \frac{\bar{p}_{K M}\left(1+\bar{t}_{K M}\right)}{p_{K M}\left(1+t_{K M}\right)}\right)^{\sigma^{K}}
\end{gathered}
$$

Supply of capital to the domestic and foreign market:

$$
\begin{gathered}
\frac{K D_{h}}{\overline{K D}_{h}}=\left(\frac{\bar{p}_{K S, h}}{p_{K S, h}} \frac{p_{K D}\left(1-t_{I, h}\right)}{\bar{p}_{K D}\left(1-\bar{t}_{I, h}\right)}\right)^{\sigma^{K S}} \\
\frac{K X_{h}}{\overline{K X}_{h}}=\left(\frac{\bar{p}_{K S, h}}{p_{K S, h}} \frac{p_{K X}}{\bar{p}_{K X}}\right)^{\sigma^{K S}}
\end{gathered}
$$




\section{I.4.3 Market Clearing Conditions}

Armington good:

$$
A_{s}=\sum_{s s} A_{s, s s}+\sum_{c} A_{s, c}+A_{s, S T K}+A_{s, G}+A_{s, I}
$$

Capital:

$$
\sum_{h} \bar{K}_{h}+K M=K X+K D+K M=K X+K=K X+\sum_{s} K_{s}
$$

Labour and leisure:

$$
\left(1-u_{s g}\right) \sum_{h}\left(\bar{L}_{h, s g}-L E_{h, s g}\right)=\sum_{s} L_{s, s g}
$$

Consumption goods:

$$
C_{c}=\sum_{h} C_{c, h}
$$

Balance of payments:

$$
B O P=\overline{B O P}=\sum_{s}\left(p_{X, s} X_{s}-p_{M, s} M_{s}\right)
$$

All other market clearing conditions are trivial, because they consist only of a single demand and a single supply component.

\section{I.4.4 Household Budget Constraints}

Budget constraints of private households (extended income):

$$
Y_{h}=p_{U, h} U_{h}=p_{K S, h} \bar{K}_{h}+\left(\sum_{s g} p_{L S, h, s g} \bar{L}_{h, s g}-T A_{h}\right)\left(1-t_{I, h}\right)+\overline{T R}_{h}-\bar{I}_{h}
$$


Government budget constraint:

$$
\begin{aligned}
p_{G} G=\sum_{s}\left(t_{Y, s} p_{Y, s} Y_{s}+t_{M, s} p_{A, s} M_{s}\right)+\sum_{s, s g} t_{P R, s g} p_{L, s g} L_{s, s g} \\
\quad+t_{K M} p_{K M} K M+\sum_{c, h, V A T} t_{V A T} p_{p, c} C_{c, h, V A T} \\
+\sum_{h} t_{I, h}\left(p_{K D, h} K D_{h}+\sum_{s g}\left(1-u_{s g}\right)\left(\bar{L}_{h, s g}-L E_{h, s g}\right) p_{L, s g}-T A_{h}\right) \\
\quad+\sum_{h} t_{S, h}\left(\sum_{s g}\left(1-u_{s g}\right)\left(\bar{L}_{h, s g}-L E_{h, s g}\right) p_{L, s g}\right) \\
\quad-\sum_{h} \overline{T R}_{h}-\sum_{s} p_{A, s} A_{s, S T K}-\overline{B O P}-\sum_{s g, h} u_{s g}\left(\bar{L}_{h, s g}-L E_{h, s g}\right) \frac{p_{C, h}}{\bar{p}_{C, h}} b
\end{aligned}
$$

\section{I.4.5 Additional Equations for Unemployment}

The supply price of labour is a weighted average of the after-tax wage and the unemployment benefit, which is indexed to the consumer price index:

$$
\frac{p_{L S, h, s g}}{\bar{p}_{L S, h, s g}}=\left(1-u_{s g}\right) \frac{p_{L, s g}}{\bar{p}_{L, s g}}\left(1-t_{S, h}-t_{I, h}\right)+u_{s g} \frac{p_{C, h}}{\bar{p}_{C, h}} b
$$

The unemployment rate is determined through a wage curve, which depends on the coefficient of residual income progression. We assume that the tax rates of the median household $(h=M)$ are the relevant ones:

$$
\frac{u_{s g}}{\bar{u}_{s g}}=\frac{1-\bar{t}_{I, M}\left(1-\frac{\overline{T A}_{M}}{\bar{Y}_{M}}\right)}{1-\bar{t}_{I, M}} \frac{1-t_{I, M}}{1-t_{I, M}\left(1-\frac{T A_{M}}{Y_{M}}\right)}
$$

